\title{
A supplementary note on the feeding behavior of the lizard
}

\section{Anolis carolinensis}

\author{
GORDON M. BURGHARDT \\ University of Tennessee, Knoxville, Tenn. 37916
}

Recently this journal published a paper entitled, "Effects of prey movement and background on predatory behavior of chameleons," by Askew et al (1970). Several aspects of this paper are open to critical scrutiny.

The report opens with the assertion that "An examination of the literature indicates that very little has been done on feeding behavior in reptiles." No references are given to support this exceedingly general statement. Moreover, in the entire article only one possibly relevant citation is made-and that to a very broad secondary source. The statement is, in fact, untrue. A considerable literature, particularly in biological journals, exists on feeding in reptiles; a most cursory examination of Biological Abstracts or Zoological Abstracts would have uncovered some of this. Even a semipopular book such as Oliver (1955) contains a wealth of information. Although some of this information is not experimental, it can be ignored by the experimentalist only to his own detriment, as the ethologists have been telling comparative psychologists for years. There actually are a considerable number of published experimental studies, going back 50 years or more, too numerous to be listed here. At least three have been published in Psychonomic Science itself (Burghardt 1966, 1967; Morris \& Loop, 1969). Although the literature on reptiles is less voluminous when compared to that of other vertebrate groups, such as birds and mammals, the blanket opening statement by Askew et al is clearly not warranted.

Let us examine the specific problem looked at by Askew et al. The standard herpetological literature contains a paper entitled, "Effects of prey size and movement on the feeding behavior of the lizards Anolis carolinensis and Eumeces fasciatus" (Burghardt, 1964). This study utilized the same predator lizard species as did Askew et al (which they improperly identified in their title), and the same prey species, mealworms (Tenebrio molitor larvae). The same major result is reported in both papers: movement of the prey was of primary importance. In addition, this writer showed that size was also a factor, whereas Askew et al demonstrated that the background substrate was an additional minor factor. The generality of the importance of movement is attested to by the fact that I used both isolated and grouped $S s$ in a simultaneous choice situation, while Askew et al used grouped Ss and a successive discrimination procedure.

There are several other methodological differences between the studies, but one more needs to be discussed here. Askew et al produced dead nonmoving mealworms by freezing them and thawing them $24 \mathrm{~h}$ later. In planning my study, I first tried this seemingly efficient method. However, I discarded it in favor of a water injection procedure for two reasons. First, $24 \mathrm{~h}$ of freezing frequently did not kill the worm; when it thawed, it mischievously began to twitch and then to crawl around. Although this could easily be solved by freezing at lower temperatures or for longer periods, a second more serious problem developed. The frozen mealworms often turned dark rather quickly upon being thawed and exposed to air. This produced a clear visual difference which could very well have an effect on the lizard's visual response. Interestingly enough, this phenomenon did not seem to have been experienced by Askew et al; they specifically state that their "freezing procedure did not appear to the E's to alter the physical appearance of the worms significantly." A possible reason for this discrepancy is not immediately evident.

This note is not a criticism of the experiment itself; after all, it repeats my own results. Nor do I want to discourage workers from studying reptile behavior. I am convinced, however, that science is best served when investigators are aware of the historical background and literature of the problem area they select and when they possess a healthy regard for the possible relevance of related disciplines. In this era of expanding information and specialization, scholarship becomes increasingly indispensable.

\section{REFERENCES}

ASKEW, H. R. MUSIMECI, M., SLOANE, L. \& STEPHAN, L. Effects of prey movement and background on predatory behavior of chameleons. Psychonomic Science, 1970, 20, 171.

BURGHARDT, G Effects of prey size and movement on the feeding behavior of the lizards Anolis carolinensis and Eumeces fasciatus. Copeia, 1964, 576-578.

BURGHARDT, G, M. Stimulus control of the prey attack response in naive garter snakes. Psychonomic Science, 1966, 4. 37-38.

BURGHARDT, G. M. The primacy effect of the first feeding experience in the snapping turtle. Psychonomic Science, $1967,7,383-384$.

MORRIS, D. D., \& LOOP, M. S. Stimulus control of prey attack in naive rat snakes: A species duplication. Psychonomic Science, 1969, 15, 141-142.

OLIVER, J. The natural history of North American amphibians and reptiles. Princeton: van Nostrand, 1955.

\section{Reply to Burghardt}

\section{HENRY R. ASKEW and MARILYN MUSIMECI \\ Fordham University, Bronx, N.Y. 10458}

We would like to reply to Burghardt's (1971) criticisms of our Psychonomic Science article (Askew, Musimeci, Sloane, \& Stephan, 1970). First, we would like to admit our error in overlooking Burghardt's (1964) study, which also dealt with feeding behavior in Anolis carolinensis. We want to point out, however, that not only did the two experiments differ in major ways procedurally and in terms of a second independent variable investigated, but our paper reported some incidental observations which were made, dealing with a possible interaction between dominance and feeding behavior, which may be the most interesting aspect of the paper in terms of suggesting a direction for further study.
Secondly, Burghardt has taken strong exception to our statement concerning the state of the literature on feeding behavior in reptiles. It is understandable how a worker who has done several studies in this area may disagree with our characterization, but when the area is objectively viewed from the perspective of researchers interested in entering a new problem area, the impression that very little has been done appears accurate and is certainly not "untrue" and "not warranted," as Burghardt argues. Certainly, experimental studies have been done, but the work appears scattered and to have advanced little beyond the preliminary exploration of a few major factors which contribute to feeding behavior. We did not say, 
nor did we mean to imply, that nothing had been done in this area, but rather that the area has been subject to comparatively little investigation when one views it within the context of many other areas of research in animal behavior. Merely citing a few of the studies that have dealt with predatory behavior in reptiles does not refute this argument.

Finally, Burghardt comments on a difference in methodology between his study and our own. Burghardt had difficulty with the freezing method we employed and rejected it because the animals either survived the procedure or turned dark brown. We did encounter similar effects, but only for a small portion of the mealworms. A few mealworms did survive, and a few did turn dark brown; however, most did not, and only those which visually appeared to be their natural color were used as prey. An explanation for the difference in the effectiveness of these procedures may lie in the variable of freezing temperature or in the variables of the genetic composition, variation in natural coloration (in our population, individuals ranged from a light yellow to a medium yellow-brown), or health of the mealworm populations. Another possibility involves the degree to which the dead animals had dried out prior to testing. The animals do, in fact, turn a dark brown when they dry out completely. In this connection, there might have been some sort of a difference between the two procedures, such as different types of containers, number of mealworms thawing in close proximity to one another, humidity and ventilation of the room, etc., which might have affected the speed with which drying occurred.

\section{ASKEW $H$ REFERENCES}

$R .$, MUSIMECI, M. L., \& STEPHAN, L. Effects of prey movement and background on predatory behavior of chameleons. Psychonomic Science, 1970, 20, 171

BURGHARDT, G. Effects of prey size and movement on the feeding behavior of the lizards Anolis carolinensis and Eumeces fasciatus. Copeia, 1964, 576-578.

BURGHARDT, G. A supplementary note on the feeding behavior of the lizard Anolis carolinensis. Psychonomic Science. $1971,23,49$.

\title{
Aftereffects of low intensity UHF radiation*
}

\author{
SUSAN F. KORBEL, KENNETH D. JOHNSON, and PAUL S. ROWLAND \\ University of Arkansas, Fayetteville, Ark. 72701
}

Thirty naive male albino rats were used as Ss in an experiment designed to determine possible behavioral aftereffects of UHF radiation. Fifteen experimental Ss were exposed to UHF of low frequency $(500 \mathrm{MHz})$ and low intensity $(.43-.15 \mathrm{~mW})$ for 38 consecutive days. For Days $39-55$, UHF was not presented to experimental Ss. UHF rats were less active than nonUHF rats and continued to be less active for a short period of time after UHF termination.

Investigations of the effects of ultra-high-frequency (UHF) radio fields, a frequency range from 300 to $3,000 \mathrm{MHz}$, have demonstrated consistent behavioral changes in albino rats. In these investigations (Korbel \& Thompson, 1962, 1965; Korbel \& Fine, 1967; Korbel, 1970), rats were exposed to relatively long-term UHF radiation at low intensities and low frequencies. Radiated rats showed the following behavioral changes relative to the nonradiated rats: (1) hypoactivity, which may be preceded by a short-term period of hy peractivity, (2) greater emotionality, (3) longer latency of recovery from electroconvulsive shock,

* This research was supported in part by a United States Public Health Service grant, No. EC00116-03 (formerly No. RH00530).
(4) longer time to swim a 16-choice water maze, and (5) a differential stress reaction as indicated by adrenal-weight/body-weight ratios. These experiments also point to the importance of two parameters: (1) range of frequency, in that a lower range is more effective in producing behavioral changes than is a higher range, and (2) duration, in that some period of time is required for low-intensity UHF to have an effect on behavior. Although these experiments demonstrate that behavioral changes do occur as a result of UHF radiation, none of them were designed to test for the permanency of the changes. The purpose of the present experiment, therefore, was the investigation of possible residual activity differences subsequent to the termination of the UHF field.

\section{SUBJECTS}

Thirty 22-day-old naive male Sprague-Dawley rats were used as Ss. Ss were assigned randomly to the UHF or nonUHF groups by the use of a table of random numbers.

\section{APPARATUS}

The UHF signal was generated by the use of an amplitude-regulating power supply (General Radio 1263A) and an oscillator with a frequency range from 250 to $920 \mathrm{MHz}$ (General Radio 1209B). A circular discone antenna, resonant on the frequencies used, directed the radio waves to the experimental Ss in their Plexiglas living cages. The living cages were placed in a circle around the antenna so that each $S$ was neither more than $25^{1 / 2}$ in. nor less than $15^{1 / 2}$ in. from the antenna.

Experimental and control groups lived in separate, identical compartments ( $7 \mathrm{ft} 9$ in. $x 5 \mathrm{ft} 9$ in. $x$ $4 \mathrm{ft})$ lined with bronze screening. The living cages for each group were enclosed in a smaller bronze cage $(5 \mathrm{ft}$ $x \quad 5 \mathrm{ft} \quad x \quad 1 \mathrm{ft} 3 \frac{1 / 2}{\mathrm{in}}$.). All bronze shielding in the experimental compartment was grounded through four 6-ft rods which were driven into earth ground. The bronze shielding in the experimental compartment was used to contain the UHF field within the experimental compartment, while the shielding in the control compartment was used only to provide environmental conditions identical to those in the experimental compartment. In order to insure that the power level was held constant and contained within the experimental compartment, daily power level measurements were made with a power meter (Hewlett-Packard 431A).

Activity measurements were made by using an activity platform (Lafayette A-501) connected to an arc suppression impulse counter (Lafayette 5707PS).

Room temperatures were recorded daily from thermometers placed in the experimental compartment, the control compartment, and the behavioral testing room. For any given day, temperatures at these locations did not vary, and the day-to-day temperature was maintained between $74^{\circ}$ and $77^{\circ} \mathrm{F}$ throughout the experiment.

\section{PROCEDURE}

For 38 consecutive days, 15 experimental Ss were exposed to UHF of low frequency $(500 \mathrm{MHz})$ and low intensity $(.43-.15 \mathrm{~mW})$, as measured at the front and back of the living cages, respectively; power level measurements were made inside the cages without the presence of the rat.) Since the experimental Ss were radiated at all times other than the times when behavioral measures were 